\title{
Effects of graphene oxide on PCR amplification for microbial community survey
}

Shuzhen $\mathrm{Li}^{1,2}$, Zhujun Wang ${ }^{1,3}$, Yuanyuan Wang ${ }^{4}$, Maoyong Song ${ }^{4}$, Guangxin Lu ${ }^{5}$, Ning Dang ${ }^{5}$, Huaqun Yin ${ }^{6}$, Yuanyuan $\mathrm{Qu}^{2}$ and Ye Deng ${ }^{1,3^{*}}$

\begin{abstract}
Background: Graphene oxide (GO) has been suggested as an efficient assistant additive to eliminate non-specific amplification of the polymerase chain reaction (PCR). Although many studies have focused on exploring its molecular mechanism, the practice of $\mathrm{GO}$ on the quantitation of microbial community has not been implemented yet. In this study, GO was added in PCR system to explore the changes on removing typical amplification errors, such as chimera and mismatches on two kinds of mock communities (an evenly mixed and a staggered mock communities) and environmental samples.
\end{abstract}

Results: High-throughput sequencing of bacterial and fungal communities, based on 165 rRNA genes and internal transcribed spacers (ITS) respectively, showed that GO could significantly increase large segmental error (chimeric sequence) in PCR procedure while had no specific effect on point error (mismatched sequence). Besides, GO reduced the a-diversity of community, and changed the composition of fungal community more obviously than bacterial community.

Conclusions: Our study provides the first quantitative data on microbial community level to prove the negative effect of $\mathrm{GO}$, and also indicates that there may be a more complex interaction between $\mathrm{GO}$ and comprehensive DNA fragments in PCR process.

Keywords: Oxidized graphene, Bacteria, Fungi, Chimera, Community composition

\section{Background}

In recent years, the study of environmental microbiome is undergoing a great revolution by the development of next-generation sequencing approaches and the establishment of robust bioinformatic tools $[1,2]$. The sequential steps of conducting a microbiome study have been systematic and comprehensive raised by researchers [3].

\footnotetext{
* Correspondence: yedeng@rcees.ac.cn

${ }^{1}$ CAS Key Laboratory of Environmental Biotechnology, Research Center for Eco-Environmental Sciences, Chinese Academy of Sciences, Beijing 100085, China

${ }^{3}$ College of Resources and Environment, University of Chinese Academy of Sciences, Beijing 100049, China

Full list of author information is available at the end of the article
}

After preliminary works finished, for example, sample collection and DNA extraction, PCR-based marker gene survey methods are applied. A segment of a conserved sequence such as the $16 \mathrm{~S}$ ribosomal RNA (rRNA) gene for bacteria, or internal transcribed spacers (ITS) region for fungi, is amplified and sequenced, to quantify and visualize the microbial community composition, distribution and diversity that made up by operational taxonomic units (OTUs).

It has been a common consent that PCR has become one of the most ubiquitous and important tools in molecular biology since it was developed in 1985 [4]. However, the amplification efficiency of PCR often decreased with the

(c) The Author(s). 2020 Open Access This article is licensed under a Creative Commons Attribution 4.0 International License, which permits use, sharing, adaptation, distribution and reproduction in any medium or format, as long as you give appropriate credit to the original author(s) and the source, provide a link to the Creative Commons licence, and indicate if changes were made. The images or other third party material in this article are included in the article's Creative Commons licence, unless indicated otherwise in a credit line to the material. If material is not included in the article's Creative Commons licence and your intended use is not permitted by statutory regulation or exceeds the permitted use, you will need to obtain permission directly from the copyright holder. To view a copy of this licence, visit http://creativecommons.org/licenses/by/4.0/. The Creative Commons Public Domain Dedication waiver (http://creativecommons.org/publicdomain/zero/1.0/) applies to the data made available in this article, unless otherwise stated in a credit line to the data. 
production of non-specific DNA fragments, especially in multiple-round PCR. Till now, many factors have been found to affect the specificity of PCR, such as chimeric reads, primer mismatches or amplification mismatches and sequencing errors, which are frequently included in the PCR mixture [5-9]. Usually, when the concentration of template DNA is very low, or the structure of DNA template is very complicated, such as GC-rich gene or mammalian genomic DNA, the specificity of PCR might be very low [10].

Graphene, with its huge surface area, has excellent electronic conductivity, heat transfer and mechanical strength properties, which make it a remarkable candidate for biological applications [11]. Graphene oxide (GO) is an oxidized form of graphene, incorporated with oxygen-containing groups on the surface, such as epoxy, hydroxyl and carboxyl groups, resulting in high polarity and hydrophilicity [12, 13]. Recently, Graphene oxide has been suggested as an efficient assistant additive to eliminate non-specific amplification of the polymerase chain reaction [14, 15]. Some mechanisms have been proposed so far are as follows. (1) Enhanced thermal conductivity [16]. The enhanced heat transfer effect of nanoparticles has been a widely accepted notion. The presence of GO in PCR amplification helps a better dissipation of heat in all denaturation, annealing and extension steps, which makes these processes more rapidly. Good heat dissipation may be due to collision among GO, base fluid molecules, and PCR reagents. Reaction components aggregated around GO increase the efficient of dynamical contact among reaction components, hence it may result in heat equilibrium in the reaction and enhance PCR efficiency. (2) Interaction of DNA polymerase with GO $[10,17]$. As GO surface is negatively charged, the adsorbed amount of positively charged Pfu polymerase and $\mathrm{Mg}^{2+}$ is relatively high at low GO concentration. As a result, PCR reagents such as dNTPs, DNA template and primers with negatively charged are attracted by positively charged $P f u$ polymerase on GO surface. Thus, the probability of mismatch is decreased and the specificity of PCR is improved. (3) Binding of DNA and GO $[18,19]$. PCR reagents such as primers and single-stranded DNA can selectively stack to GO, which prevents their self-folding and thus improves the sensitivity and specificity of PCR by enhancing the efficiency of the base-pairing between the primers and template. Although many studies have been focusing on exploring the influence of GO on PCR procedure by electrophoresis, what the specific effects by the addition of GO would have on the number of typical amplification errors, such as chimeras and mismatches, has not been systematically studied. Besides, whether GO will improve the PCR performance for the survey of microbial community, such as the influences on community composition and diversity, has not been explored yet.

Here in this study we explore the effect of GO on removing amplification errors, including chimeric and mismatched sequences on two kinds of mock communities (an even and a staggered mock communities) and environmental samples, as well as its contribution on the changes of community diversity and composition.

\section{Results}

\section{GO affects amplification errors in mock communities}

Sequences of mock communities were filtered based on quality score, and retained sequences were firstly used to explore the influence of GO on chimeras and mismatches. As shown in Fig. 1, the addition of GO in PCR showed a great effect on chimera formation. More chimera generated in GO groups, especially for staggered bacterial mock community $(P=0.006)$, as well as evenly mixed $(P=0.007)$ and staggered $(P=0.048)$ fungal mock communities. Bacterial community generated a larger proportion of chimeric sequences than fungal community in both even and staggered mock communities, and it seemed that chimera proportion increased more significantly in fungi than in bacteria after the addition of GO (Fig. 1). Instead, we observed that GO showed litter impact on mismatch (Fig. 2). In any kinds of the mock communities of bacteria and fungi, there was no significant difference between control and GO groups in most of the mismatch numbers $(P>0.05)$, except for one and two mismatches in even fungal mock community.

\section{GO changes the composition of environmental communities}

The next important question is whether GO can change the composition of microbial community. After removing chimeric sequences, OTUs were generated and we compared the abundance of samples in control and GO groups in mock community. Results showed that there was no significant increase or decrease in relative abundance in both even and staggered mock communities for bacteria and fungi $(P>0.05)$ (Fig. 3$)$.

To further validate the results and reduce deviations from the mock community, 24 soil samples were collected. After all quality control process, a total of 1,922, 267 and 849,199 sequences were obtained for bacterial and fungal communities, respectively (Table S1). OTUs were generated and the average sequence numbers of each sample were 53,300 and 33,846 for bacterial and fungal communities, respectively (Table S2). Samples were randomly sub-sampled to an equal depth, and three kinds of $\alpha$-diversity indexes, including richness, Shannon index and phylogenetic diversity were measured. Results showed that the addition of GO reduced 


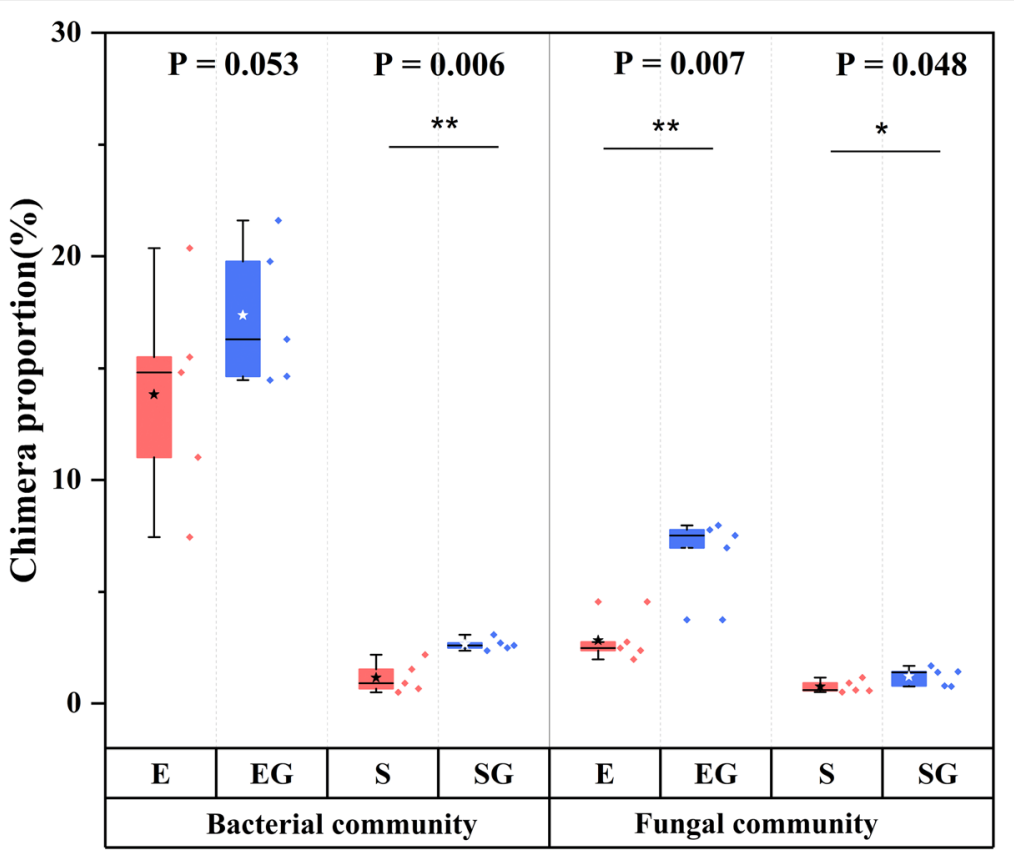

Fig. 1 Detected chimera proportions in mock communities. E, even mock community; EG, even mock community with GO; S, staggered mock community; SG, staggered mock community with GO. Star in boxplot is the average value

$\alpha$-diversity in bacterial and fungal communities (Fig. 4, Table S3). We further assessed taxonomic differences on phylum level between control and GO groups in environmental samples by response ratio analysis [20]. After replacing $\mathrm{ddH}_{2} \mathrm{O}$ to $\mathrm{GO}$ in PCR protocol, bacterial communities did not show a significant change (Fig. 5a). Abundances of Actinobacteria and Gemmatimonadetes had a slight rise, abundances of Firmicutes and Planctomycetes decreased, and other main phyla remained almost unchanged. In fungal communities (Fig. 5b), abundance of Ascomycota had a significant decrease. Basidiomycota also showed a decreased abundance, and abundances of Zygomycota, Glomeromycota, and Chytridiomycota went up, while the differences were no significant between control and $\mathrm{GO}$ groups.

\section{Discussion}

\section{Effect of GO on PCR amplification and microbial} community

Chimeras and mismatches are two kinds of typical amplification errors, which are easy to appear in PCR process and greatly reduce its specificity. Chimeras are hybrid products formed from two or more biological sequences during PCR process. The most common mechanism is believed to be incomplete template extension in which arise most chimeras. When the sequences are amplified in conserved regions, such as bacterial $16 \mathrm{~S}$ rRNA or fungal ITS region, chimera is more likely to occur and further bring biases to downstream analysis [21]. Besides, in the dozens of cycles of PCR amplification, it is impossible to ensure that any points of a single sequence do not mismatch. Every mismatch will cause non-specific amplification in the next PCR cycle. Hence, it is very important to examine whether GO has an effect on the occurrence of chimeras and mismatches.

From our results, it could be speculated that GO affected large segmental errors during amplification, that is, significantly increased the number of chimeric sequences (Fig. 1). Meanwhile, GO showed no obvious effect on point errors of single or multiple nucleotides, i.e. mismatched sequences (Fig. 2). Although previous studies have demonstrated that GO can act as an efficient assistant additive to eliminate non-specific amplification $[10,14]$, our study provides the quantitative data on microbial community level to prove the negative effect of GO. On the other hand, these observations are based on our mock communities. The mock community has been demonstrated to be a good positive control with a known set of qualitative and quantitative compositions to explore the dynamic changes of microbial diversity and composition [22, 23]. The relatively small number of species used to construct mock communities may limit the further generalization of our results. Nonetheless, our results were enough to indicate that GO will not promote PCR for all microbial communities, on the contrary, GO can perform adverse effects on PCR efficiency for some bacterial and fungal taxa.

After incorporating environmental samples into the study, we found that there was a dynamic change of community diversity and composition (Figs. 4, 5). We 

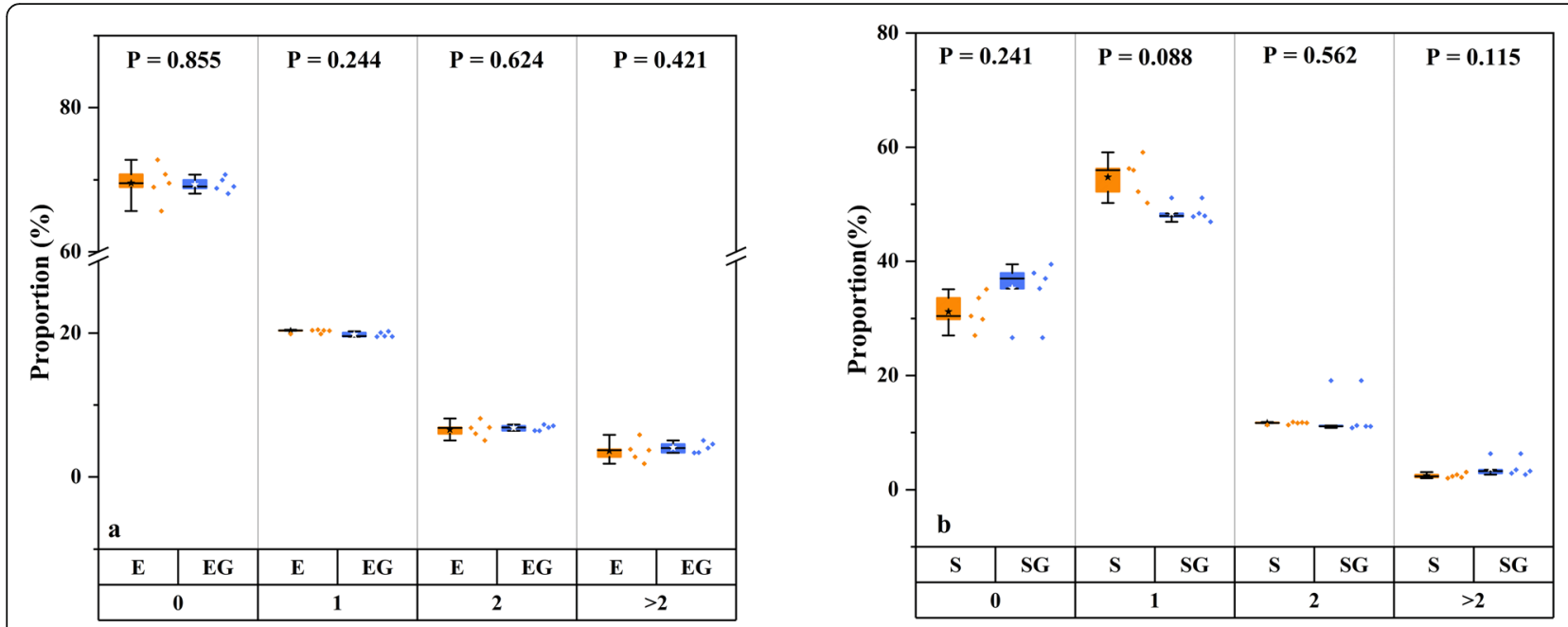

Mismatch number
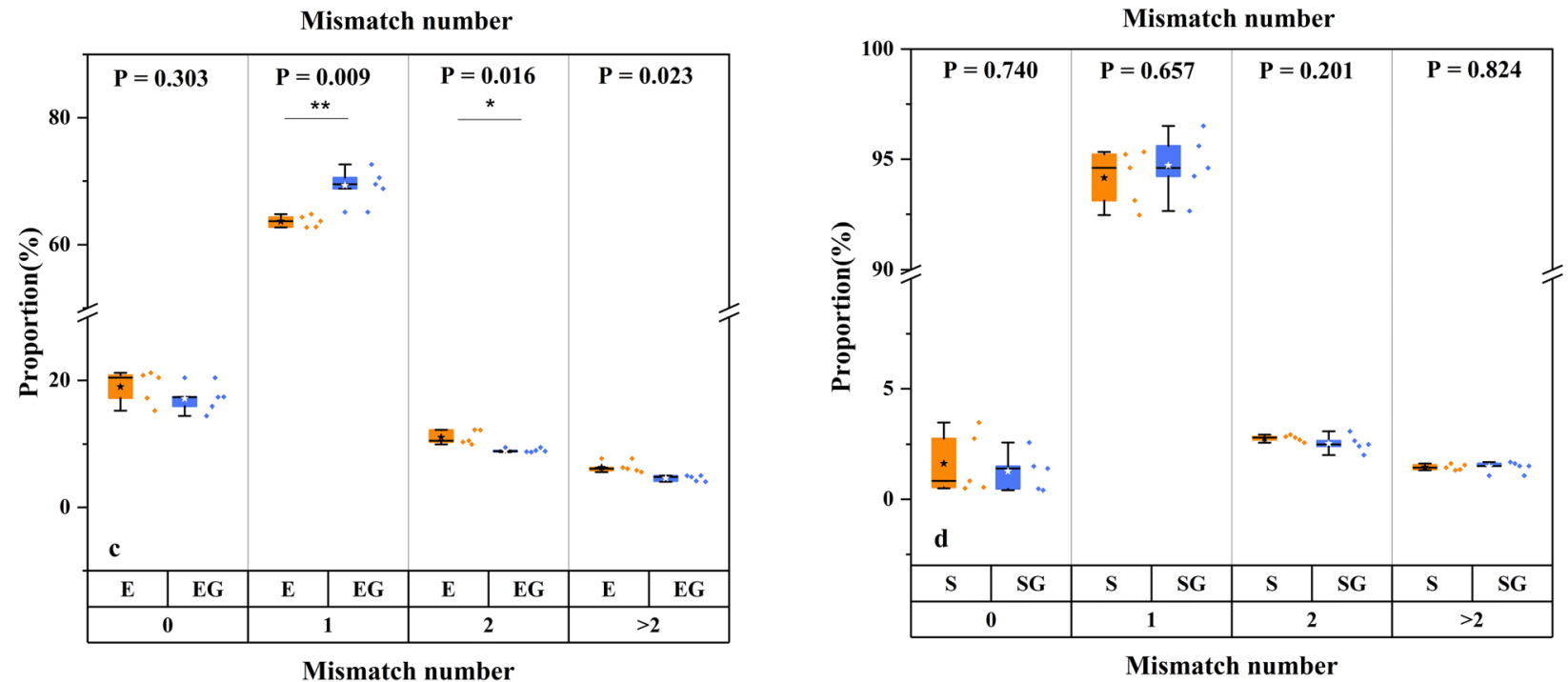

Fig. 2 Mismatched sequences. a even bacterial mock community; (b) staggered bacterial mock community; (c) even fungal mock community (d) staggered fungal mock community. Star in boxplot is the average value

proposed two possible reasons for community changes. Firstly, according to previous studies, the addition of GO effectively reduce non-specific amplification [14, 15]. Based on this we can speculate that GO may reduce the OTU inflation, which leads to more accurate community structure. Secondly, based on the results of our previous mock community, GO may have made some species more prone to generate incomplete amplification, thus more chimera appeared. More chimeric sequences for some taxa are removed during the quality control process, resulting in decreases in diversity and variations in composition of microbial community.

\section{The effect of GO on DNA may be more complicated than expected}

Previous studies have proved that GO can eliminate non-specific amplification effectively $[14,15]$. However, their conclusions and proposed mechanisms lack quantitative data at the community level. Meanwhile, interactions between GO and DNA have been widely studied in many fields, and researches have indicated that GO has strong toxicity to DNA through the destructive effect [24]. Besides, the double helix structure of DNA could be disrupted by graphene-based nanoparticles through strong dispersive forces [25]. More generally, other studies have been focusing on the interactions between various metal oxide nanoparticles materials and DNA amplification, and both of inhibition and enhancement effects have been observed extensively in independent researches. PCR experiments have given evidence that multiple nanoparticles (e.g. $\mathrm{ZnO}, \mathrm{CeO}_{2}$, citrate-stabilized AuNPs and AgNPs) can inhibit DNA amplification [26]. Nanoparticles can bind to DNA to change the normal conformation of DNA molecules, and this high affinity 

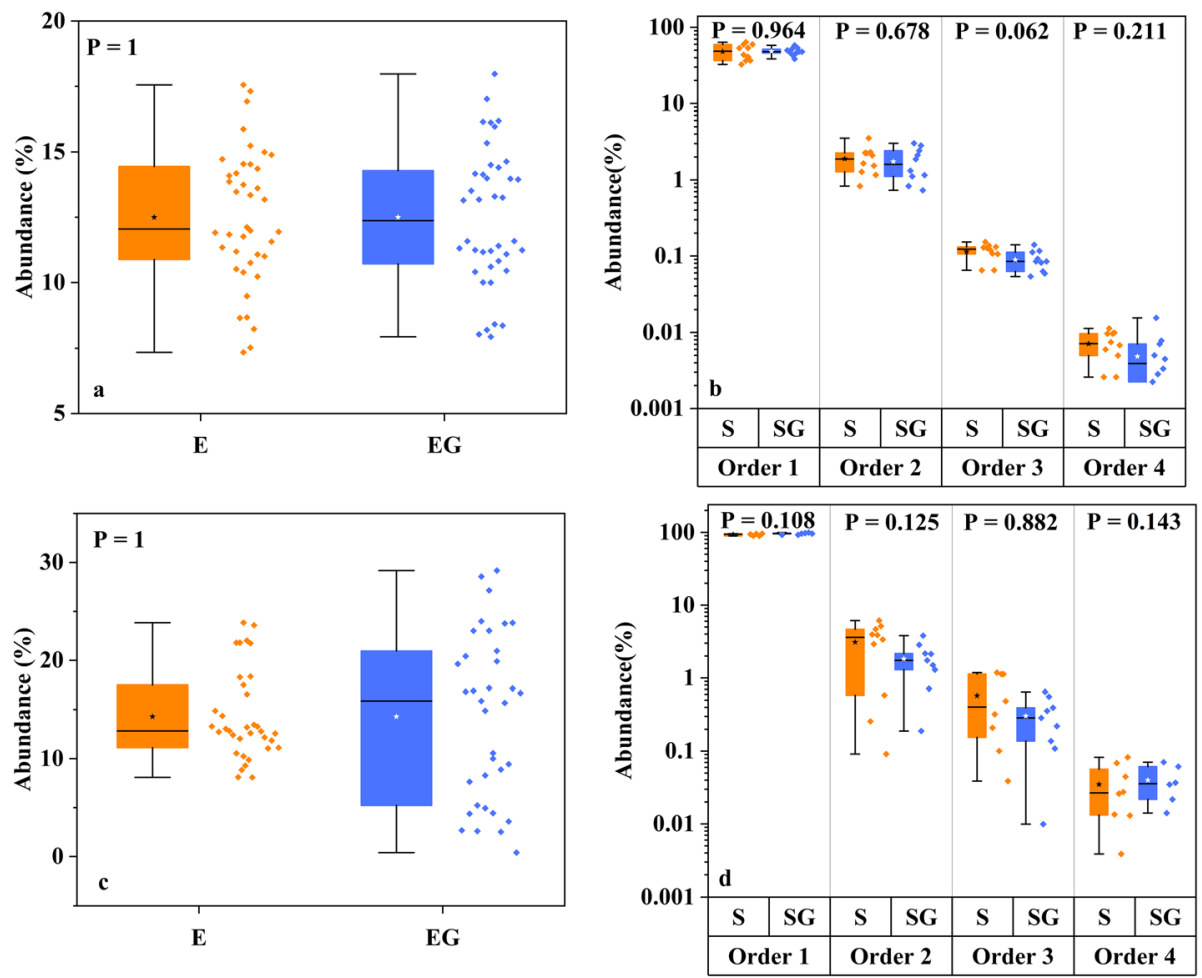

Fig. 3 Even and staggered mock community mean abundance. a even bacterial mock community; (b) staggered bacterial mock community; (c) even fungal mock community (d) staggered fungal mock community. Star in boxplot is the average value

can further inhibit the functions of DNA polymerases [27-29]. On the contrary, some types of nanoparticles (e.g. $\mathrm{Fe}_{3} \mathrm{O}_{4} \mathrm{NPs}$ and colloidal AuNPs) have the ability to promote PCR specificity, efficiency or yield [30-33]. Considering all knowledge, the influence of GO on DNA may be a combination of promoting and toxic effects. In the complex PCR mixture, GO enhances thermal conductivity, binds DNA and interacts with DNA through electrical charge, these can improve the specificity of PCR. But at the same time, GO also performs destructive or inhibitory functions as a typical graphene-based nanoparticle. Moreover, the impact of GO may have species-specific effect, different types of microbes may have differential responses under GO exposure [34]. GO can modify and shape the microbial community structure through inducing inhibition or promotion of particular species' DNA replication, which may account for the community changes [34-37].

\section{Conclusions}

The results presented in this study represent important contributions to understand the effect of $\mathrm{GO}$ on the generation of chimeric and mismatched sequences, and the change of composition and diversity of microbial communities. GO significantly increases chimeric sequences but shows no specific effect on mismatch. Besides, GO reduces the alpha diversity of environmental community, and changes community composition more obviously in fungal community than in bacterial community. Our study provides the first quantitative data on microbial community to prove the negative effect of GO, and proposes that there may be a more complex interaction between GO and DNA in PCR process. Our research makes a preliminary exploration on community level, and future studies are needed to take a closer look at the role of $\mathrm{GO}$ and the mechanisms behind it.

\section{Methods}

\section{Construction of mock community}

Bacterial and fungal mock community were constructed by eight different species, respectively. For bacterial mock community, species derived from eight different genera, including Alcaligenes sp. (Accession number JF698681), Arthrobacter sp. (Accession number FJ851358), Bacillus sp. (Accession number KU556329), Cupriavidus sp. (Accession number KU726429), Patulibacter sp. (Accession number KT581436), Pseudomonas sp. (Accession number NZ AHGZ00000000), Terrimonas sp. (Accession number NZ AUDS01000000) and Arthrobacter sp. (Accession number NZ_JWMD01000000). For fungal mock community, species were obtained from the Agricultural Culture Collection of China (ACCC), that is Auricularia auricula (ACCC 

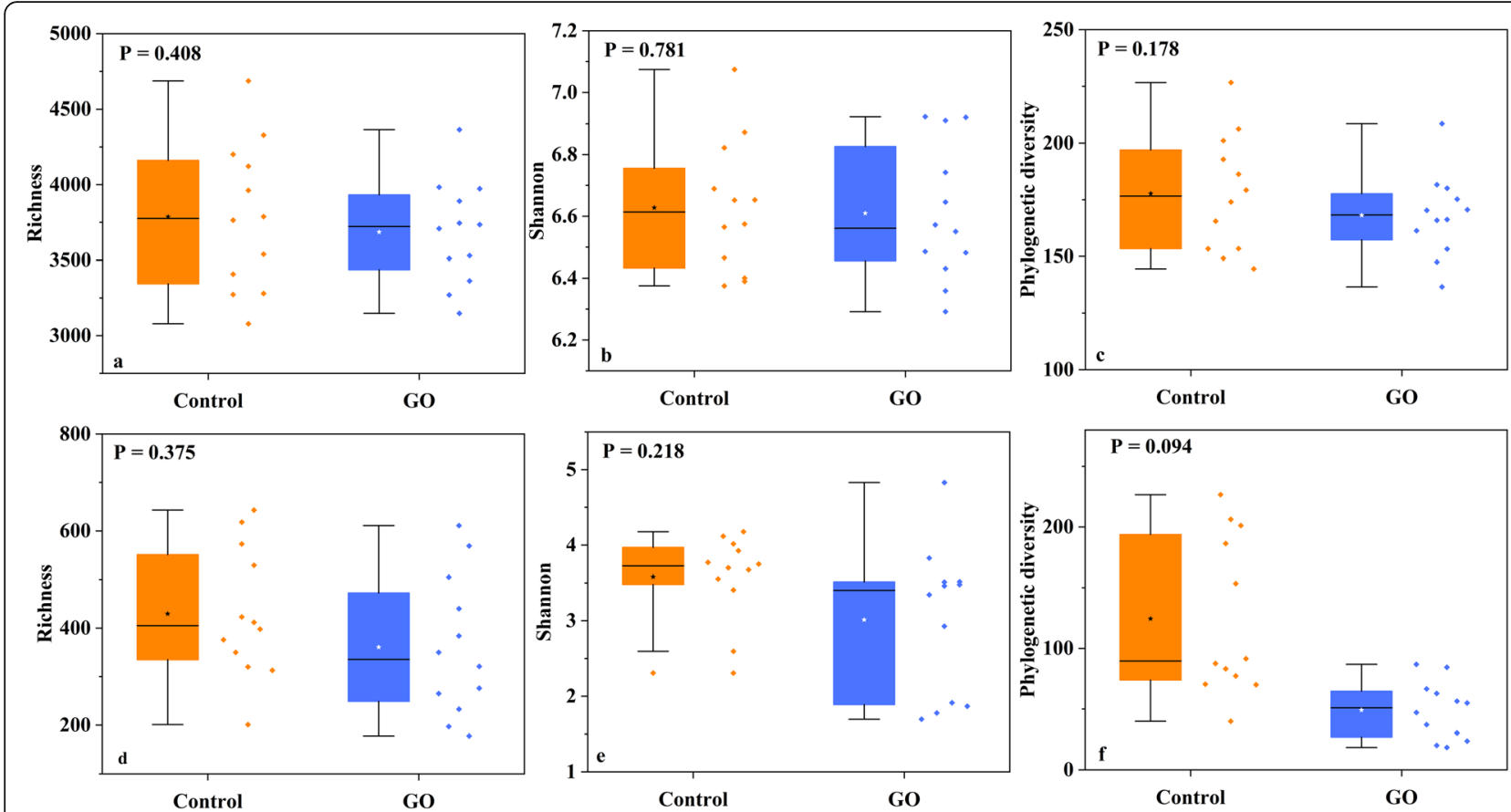

Fig. 4 Alpha diversity indexes (Richness, Shannon and Phylogenetic diversity) for environmental samples. a-c bacteria data; $\mathbf{d}$-f fungi data. Star in boxplot is the average value

number 51049), Cordyceps militaris (ACCC number 50985), Lentinula edodes (ACCC number 50749), Alternaria alternate (ACCC number 38066), Mucor racemosus (ACCC number 30522), Trichoderma reesei (ACCC number 30590), Fusarium oxysporum (ACCC number 37404) and Yarrowia lipolytical (ACCC number 20101). Then genomic DNA of each species was extracted using TIANamp DNA Kit (Tiangen biotech Co Ltd.). Full 16S rRNA gene and ITS region were amplified by pair-wise universal primer 27F (5'-AGAGTTTGATCMTGGCTCAG-3'), 1492R (5'-GGYTACCTTGTTACGACTT-3') and ITS1F (5'-CTTGGTCATTTAGAGGAAGTAA-3'), ITS4 (5' TCCTCCGCTTATTGATATGC-3'), respectively [22, 38, 39]. Next, PCR products were purified and ligated with pMD18-T vector. The recombinant plasmid was cloned into E. coli DH5 2 , and DNA was extracted by TIANpure Mini Plasmid Kit (Tiangen biotech Co Ltd.). Two kinds of mock communities were constructed with different rRNA operon counts. Specifically, even mock community consisted of eight species at equimolar rRNA operon counts (5 $\mathrm{ng} / \mu \mathrm{L})$. Staggered mock community consisted of the same species with four gradients of rRNA operon counts $(50,5$, 0.5 and $0.05 \mathrm{ng} / \mu \mathrm{L}$ ). Each type of mock community made five biological replicates to ensure the robustness of the results.

\section{Environmental samples}

Environmental microbial community samples were obtained from alpine meadow ecosystem in Qinghai province $\left(33^{\circ} 24^{\prime} 30^{\prime \prime} \mathrm{N}, 97^{\circ} 18^{\prime} 00^{\prime \prime} \mathrm{E}\right)$ with an elevation of
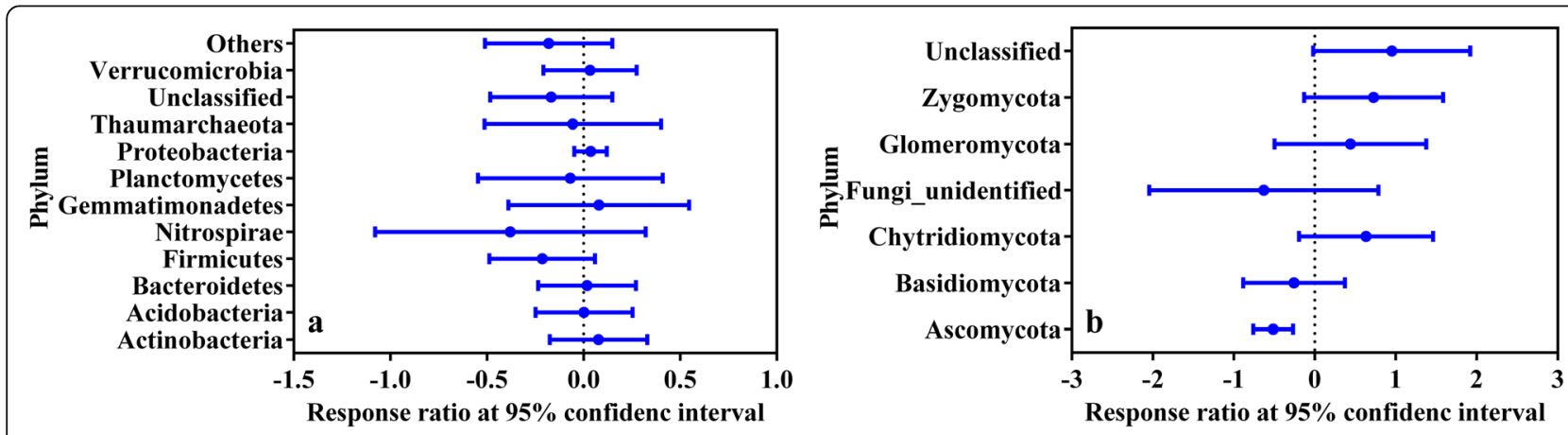

Fig. 5 Response ratio analysis of environmental community in phylum level. a bacteria data; b fungi data 
$4270 \mathrm{~m}$. Samples taken from field station belongs to the typical plateau continental climate with a mean annual rainfall of $562.2 \mathrm{~mm}$ and a mean annual temperate of $5.6^{\circ} \mathrm{C} \sim 3.8^{\circ} \mathrm{C}$ [40]. Twelve soil samples were collected from the depth of $15-30 \mathrm{~cm}$. DNA was then extracted with FastDNA ${ }^{\mathrm{T}}$ SPIN Kit for Soil (MP Biomedicals). Both of bacteria and fungi communities were amplified as follows.

PCR, library preparation and high-throughput sequencing For bacteria, V4 region of 16S rRNA gene was amplified using primers 515F (5'-GTGCCAGCMGCCGCGGTAA$\left.3^{\prime}\right)$ and 806R (5'-GGACTACHVGGGTWTCTAAT-3') [41]. For fungi, ITS2 region was amplified by gITS7 (5'GTGARTCATCGARTCTTTG-3') and ITS4 (5' -TCCTCC GCTTATTGATATGC-3') [22]. Both forward and reverse primers contained 12 unique base pair barcodes to distinguish samples. PCR conditions and library preparation are consistent with previous studies [42, 43]. Briefly, PCR mix contains $1 \mu \mathrm{L}$ of template DNA within $20-30 \mathrm{ng} / \mu \mathrm{L}, 0.5 \mu \mathrm{L}$ Taq DNA Enzyme, $1.5 \mu \mathrm{L}$ dNTP mixture, $5 \mu \mathrm{L} 10 \times$ PCR buffer, $1.5 \mu \mathrm{L}$ of both $10 \mu \mathrm{M}$ forward and reverse primers and $39 \mu \mathrm{L} \mathrm{ddH}_{2} \mathrm{O}$. The thermal cycle parameters were as follows: denaturation at $94{ }^{\circ} \mathrm{C}$ for $1 \mathrm{~min}, 30$ cycles of $94{ }^{\circ} \mathrm{C}$ for $20 \mathrm{~s}, 57^{\circ} \mathrm{C}$ for $25 \mathrm{~s}, 68^{\circ} \mathrm{C}$ for $45 \mathrm{~s}$, a final extension at $68{ }^{\circ} \mathrm{C}$ for $10 \mathrm{~min}$ and finally keep at $4{ }^{\circ} \mathrm{C}$. As for exploring GO's effect on community composition and diversity, $1 \mu \mathrm{g} /$ $\mathrm{mL}$ GO has been showed with the greatest enhancement in PCR, and $\mathrm{dd}_{2} \mathrm{O}$ was replaced by $1 \mu \mathrm{g} / \mathrm{mL}$ Go solution in our PCR system [14]. PCR products were separated by agarose gel electrophoresis and purified by Gel Extraction Kit (D2500-02, OMEGA BioTek). The purified DNA was quantified through NanoDrop 2000 Spectrophotometer (ThermoFisher, USA). All purified DNA were pooled together to construct a sequencing library and connect Illumina adapters directed by the protocol of VAHTSTM Nano DNA Library Prep Kit for Illumina ${ }^{\circ}$ Vazyme Biotech Co., Ltd) and MiSeq Reagent Kit Preparation Guide (Illumina). Pooled libraries were quantified using Qubit assay with Qubit 2.0 Fluorometer (Life Technologies). Sequencing was performed on an Illumina Miseq platform with $2 \times 250$ bp high-output run chemistry at Central South University, China.

\section{Quality control and bioinformatics approaches}

Data from sequencing was analyzed by a publicly accessible pipeline (http://mem.rcees.ac.cn:8080) [44, 45]. Briefly, primers were removed and paired-end reads were joined by FLASH [46]. The minimum required overlap was $30 \mathrm{bp}$. Low-quality sequences were discarded with the threshold of Quality Score $>20$, minimum length 140 and window size 5 by Btrim program [47]. Sequences length in 245-260 bp for bacteria, 240$320 \mathrm{bp}$ for fungi were retained for further analysis. Then, chimeras were identified and removed by different reference databases for mock and environmental communities by UCHIME algorithm [48]. For bacterial and fungal mock communities, reference databases were eight bacterial or fungal sequences that have been sequenced to build the mock community. Sequences were detected as one of the targeted species by matching up to $97 \%$ sequence identity and $90 \%$ coverage by BLAST [49]. Meanwhile, mismatch was also identified according to BLAST outputs. For environmental community, reference databases for bacterial and fungal data were Greengene 13.8 taxonomy file and Gold database, respectively. Finally, high-quality clean sequences were classified into operational taxonomic units (OTUs) at 97\% identity by UPARSE without any singletons being discarded [50].

For environmental samples, representative sequences were classified into different taxonomy by Bayesian classifier against the RDP training set and UNITE database for bacteria and fungi, respectively $[51,52]$. According to sequences numbers, randomly sub-sampled OTU tables were generated to normalize total reads by 24,300 and 15,000 for bacterial and fungal samples. Alpha diversity indexes, including richness, Shannon and phylogenetic diversity were measured using vegan package in $R$ (v.3.6.0) [53]. The significances between control and GO added groups were determined by independent and paired Student's t-test as appropriate.

\section{Supplementary information}

Supplementary information accompanies this paper at https://doi.org/10. 1186/s12866-020-01965-7.

Additional file 1.

Abbreviations

GO: Graphene oxide; PCR: Polymerase chain reaction; rRNA: Ribosomal RNA; ITS: Internal transcribed spacers; OTUs: Operational taxonomic units

\section{Acknowledgements}

Not applicable.

\section{Authors' contributions}

The research was designed by SL, YQ, MS and YD. SL, ZW, YW, GL, ND and HY performed the experiments. SL analyzed the data. SL and YD wrote the manuscript. All authors read and approved the final manuscript.

\section{Funding \\ This study was supported by the National Nature Science Foundation of China (NSFC, Grant No. 31861133002, 91851106) and the Key Research Program of Frontier Sciences, CAS (QYZDB-SSW-DQC026). The funding body had no role in study design, sample collection, analysis, interpretation of data, writing the manuscript and decision to publish.}

Availability of data and materials

The 165 rRNA gene and ITS region sequencing data analyzed in the current study are available in the NCBI Sequence Read Archive (SRA) database

(https://www.ncbi.nlm.nih.gov/sra) under the accession numbers SUB7253148, SUB7257294, SUB7257355 and SUB7257383.

Ethics approval and consent to participate

Not applicable. 


\section{Consent for publication}

Not applicable.

\section{Competing interests}

Ye Deng is an associate editor of this journal. The authors declare no conflict of interest.

\section{Author details}

${ }^{1}$ CAS Key Laboratory of Environmental Biotechnology, Research Center for Eco-Environmental Sciences, Chinese Academy of Sciences, Beijing 100085, China. ${ }^{2}$ Key Laboratory of Industrial Ecology and Environmental Engineering (Ministry of Education), School of Environmental Science and Technology, Dalian University of Technolog, Dalian 116024, China. ${ }^{3}$ College of Resources and Environment, University of Chinese Academy of Sciences, Beijing 100049, China. ${ }^{4}$ State Key Laboratory of Environmental Chemistry and Ecotoxicology, Research Center for Eco-Environmental Sciences, Chinese Academy of Sciences, Beijing 100085, China. ${ }^{5}$ College of Agriculture and Animal Husbandry, Qinghai University, Xining 810016, China. ${ }^{6}$ School of Minerals Processing and Bioengineering, Central South University, Changsha 410083, China

\section{Received: 19 April 2020 Accepted: 2 September 2020} Published online: 11 September 2020

\section{References}

1. Gilbert JA, Jansson JK, Knight R. The earth microbiome project: successes and aspirations. BMC Biol. 2014;12:69.

2. Zinger L, Amaral-Zettler LA, Fuhrman JA, Horner-Devine MC, Huse SM, Welch DBM, et al. Global patterns of bacterial Beta-diversity in seafloor and seawater ecosystems. PLoS One. 2011;6(9):e24570.

3. Goodrich JK, Di Rienzi SC, Poole AC, Koren O, Walters WA, Caporaso JG, et al. Conducting a microbiome study. Cell. 2014;158(2):250-62.

4. Scharf SJ, Horn GT, Erlich HA. Direct cloning and sequence-analysis of enzymatically amplified genomic sequences. Science. 1986;233(4768): 1076-8.

5. D'Amore R, ljaz UZ, Schirmer M, Kenny JG, Gregory R, Darby AC, et al. A comprehensive benchmarking study of protocols and sequencing platforms for 16S rRNA community profiling. BMC Genomics. 2016;17:55.

6. Haas BJ, Gevers D, Earl AM, Feldgarden M, Ward DV, Giannoukos G, et al. Chimeric 165 rRNA sequence formation and detection in sanger and 454pyrosequenced PCR amplicons. Genome Res. 2011;21(3):494-504.

7. Schirmer M, ljaz UZ, D'Amore R, Hall N, Sloan WT, Quince C. Insight into biases and sequencing errors for amplicon sequencing with the Illumina Miseq platform. Nucleic Acids Res. 2015;43(6):e37.

8. Mao DP, Zhou Q, Chen CY, Quan ZX. Coverage evaluation of universal bacterial primers using the metagenomic datasets. BMC Microbiol. 2012;12:66.

9. Klindworth A, Pruesse E, Schweer T, Peplies J, Quast C, Horn M, et al. Evaluation of general 165 ribosomal RNA gene PCR primers for classical and next-generation sequencing-based diversity studies. Nucleic Acids Res. 2013; 41(1):e1.

10. Zhong Y, Huang LH, Zhang ZS, Xiong YJ, Sun LP, Weng J. Enhancing the specificity of polymerase chain reaction by graphene oxide through surface modification: zwitterionic polymer is superior to other polymers with different charges. Int J Nanomedicine. 2016;11:5989-6002.

11. Dreyer DR, Ruoff RS, Bielawski CW. From conception to realization: an Historial account of Graphene and some perspectives for its future. Angew Chem Int Edit. 2010;49(49):9336-44.

12. He HY, Klinowski J, Forster M, Lerf A. A new structural model for graphite oxide. Chem Phys Lett. 1998;287(1-2):53-6.

13. Mkhoyan KA, Contryman AW, Silcox J, Stewart DA, Eda G, Mattevi C, et al. Atomic and electronic structure of Graphene-oxide. Nano Lett. 2009;9(3): 1058-63.

14. Wang $Y$, Wang F, Wang H, Song M. Graphene oxide enhances the specificity of the polymerase chain reaction by modifying primer-template matching. Sci Rep. 2017;7(1):16510.

15. Tong W, Cao X, Wen S, Guo R, Shen M, Wang J, et al. Enhancing the specificity and efficiency of polymerase chain reaction using polyethyleneimine-based derivatives and hybrid nanocomposites. Int J Nanomedicine. 2012;7:1069-78.
16. Khaliq AR, Kafafy R, Salleh HM, Faris WF. Enhancing the efficiency of polymerase chain reaction using graphene nanoflakes. Nanotechnology. 2012;23(45):455106.

17. Jia J, Sun LP, Hu N, Huang GM, Weng J. Graphene enhances the specificity of the polymerase chain reaction. Small. 2012;8(13):2011-5.

18. Park JS, Goo NI, Kim DE. Mechanism of DNA adsorption and desorption on Graphene oxide. Langmuir. 2014;30(42):12587-95.

19. Zhu MD, Luo C, Zhang FW, Liu F, Zhang JY, Guo SW. Interactions of the primers and $\mathrm{Mg} 2+$ with graphene quantum dots enhance PCR performance. RSC Adv. 2015;5(91):74515-22.

20. Zhang Z, Qu Y, Li S, Feng K, Wang S, Cai W, et al. Soil bacterial quantification approaches coupling with relative abundances reflecting the changes of taxa. Sci Rep. 2017;7(1):4837.

21. Bjornsgaard Aas A, Davey ML, Kauserud H. ITS all right mama: investigating the formation of chimeric sequences in the ITS2 region by DNA metabarcoding analyses of fungal mock communities of different complexities. Mol Ecol Resour. 2017;17(4):730-41.

22. Ihrmark K, Bodeker IT, Cruz-Martinez K, Friberg H, Kubartova A, Schenck J, et al. New primers to amplify the fungal ITS2 region--evaluation by 454sequencing of artificial and natural communities. FEMS Microbiol Ecol. 2012; 82(3):666-77.

23. Nguyen NH, Smith D, Peay K, Kennedy P. Parsing ecological signal from noise in next generation amplicon sequencing. New Phytol. 2015;205(4): 1389-93.

24. Akhavan O, Ghaderi E. Toxicity of graphene and graphene oxide nanowalls against bacteria. ACS Nano. 2010;4(10):5731-6.

25. Zhao XC. Self-assembly of DNA segments on Graphene and carbon nanotube arrays in aqueous solution: a molecular simulation study. J Phys Chem C. 2011;115(14):6181-9.

26. Li K, Zhao X, KH B, Du S, Chen Y. Nanoparticles inhibit DNA replication by binding to DNA: modeling and experimental validation. ACS Nano. 2013; 7(11):9664-74

27. Li K, Zhang W, Chen Y. Quantum dot binding to DNA: single-molecule imaging with atomic force microscopy. Biotechnol J. 2013;8(1):110-6.

28. Johnston HJ, Hutchison G, Christensen FM, Peters S, Hankin S, Stone V. A review of the in vivo and in vitro toxicity of silver and gold particulates: particle attributes and biological mechanisms responsible for the observed toxicity. Crit Rev Toxicol. 2010;40(4):328-46.

29. Li KG, Chen YS. Examination of nanoparticle-DNA binding characteristics using single-molecule imaging atomic force microscopy. J Phys Chem C. 2014;118(25):13876-82.

30. Kambli P, Kelkar-Mane V. Nanosized Fe3O4 an efficient PCR yield enhancercomparative study with au, Ag nanoparticles. Colloid Surface B. 2016;141: $546-52$.

31. Chen P, Pan D, Fan C, Chen J, Huang K, Wang D, et al. Gold nanoparticles for high-throughput genotyping of long-range haplotypes. Nat Nanotechnol. 2011;6(10):639-44.

32. Mi L, Wen Y, Pan D, Wang Y, Fan C, Hu J. Modulation of DNA polymerases with gold nanoparticles and their applications in hot-start PCR. Small. 2009; 5(22):2597-600.

33. Shen C, Yang W, Ji Q, Maki H, Dong A, Zhang Z. NanoPCR observation: different levels of DNA replication fidelity in nanoparticle-enhanced polymerase chain reactions. Nanotechnology. 2009;20(45):455103.

34. Gao CH, Mortimer M, Zhang M, Holden PA, Cai P, Wu S, et al. Impact of metal oxide nanoparticles on in vitro DNA amplification. PeerJ. 2019;7:e7228.

35. He SY, Feng YZ, Ren HX, Zhang Y, Gu N, Lin XG. The impact of iron oxide magnetic nanoparticles on the soil bacterial community. J Soils Sediments. 2011;11(8):1408-17.

36. Kumar A, Pandey AK, Singh SS, Shanker R, Dhawan A. Engineered ZnO and $\mathrm{TiO} 2$ nanoparticles induce oxidative stress and DNA damage leading to reduced viability of Escherichia coli. Free Radical Bio Med. 2011;51(10):1872-81.

37. Barnes RJ, van der Gast CJ, Riba O, Lehtovirta LE, Prosser Jl, Dobson PJ, et al. The impact of zero-valent iron nanoparticles on a river water bacterial community. J Hazard Mater. 2010;184(1-3):73-80.

38. Gardes M, Bruns TD. ITS primers with enhanced specificity for basidiomycetes--application to the identification of mycorrhizae and rusts. Mol Ecol. 1993;2(2):113-8.

39. Lane DJ. 16S/23S rRNA sequencing, In: Stackebrandt E, Goodfellow M, editors. Nucleic acidtechniques in bacterial systematics. New York: Wiley; 1991. p. $115-75$ 
40. Wang ZJ, Lu GX, Yuan MT, Yu H, Wang S, Li X, et al. Elevated temperature overrides the effects of $\mathrm{N}$ amendment in Tibetan grassland on soil microbiome. Soil Biol Biochem. 2019;136:107532.

41. Caporaso JG, Lauber CL, Walters WA, Berg-Lyons D, Huntley J, Fierer N, et al. Ultra-high-throughput microbial community analysis on the Illumina HiSeq and MiSeq platforms. ISME J. 2012;6(8):1621-4.

42. Li S, Deng Y, Wang Z, Zhang Z, Kong X, Zhou W, et al. Exploring the accuracy of amplicon-based internal transcribed spacer markers for a fungal community. Mol Ecol Resour. 2020;20(1):170-84.

43. Liu Y, Wang S, Wang Z, Zhang Z, Qin H, Wei Z, et al. Soil microbiome mediated nutrients decline during forest degradation process. Soil Ecol Lett. 2019;1(1):59-71

44. Zhang ZJ, Deng Y, Feng K, Cai WW, Li SZ, Yin HQ, et al. Deterministic assembly and diversity gradient altered the biofilm community performances of bioreactors. Environ Sci Technol. 2019;53(3):1315-24.

45. Feng K, Zhang Z, Cai W, Liu W, Xu M, Yin H, et al. Biodiversity and species competition regulate the resilience of microbial biofilm community. Mol Ecol. 2017;26(21):6170-82.

46. Magoc T, Salzberg SL. FLASH: fast length adjustment of short reads to improve genome assemblies. Bioinformatics. 2011;27(21):2957-63.

47. Kong Y. Btrim: a fast, lightweight adapter and quality trimming program for next-generation sequencing technologies. Genomics. 2011;98(2):152-3.

48. Edgar RC, Haas BJ, Clemente JC, Quince C, Knight R. UCHIME improves sensitivity and speed of chimera detection. Bioinformatics. 2011;27(16): 2194-200

49. Boratyn GM, Camacho C, Cooper PS, Coulouris G, Fong A, Ma N, et al. BLAST: a more efficient report with usability improvements. Nucleic Acids Res. 2013;41(W1):W29-33.

50. Edgar RC. UPARSE: highly accurate OTU sequences from microbial amplicon reads. Nat Methods. 2013;10(10):996-8.

51. Nilsson RH, Larsson KH, Taylor AFS, Bengtsson-Palme J, Jeppesen TS, Schigel $D$, et al. The UNITE database for molecular identification of fungi: handling dark taxa and parallel taxonomic classifications. Nucleic Acids Res. 2019; 47(D1):D259-64.

52. Wang Q, Garrity GM, Tiedje JM, Cole JR. Naive Bayesian classifier for rapid assignment of rRNA sequences into the new bacterial taxonomy. Appl Environ Microb. 2007;73(16):5261-7.

53. Dixon P. VEGAN, a package of R functions for community ecology. J Veg Sci. 2003:14(6):927-30.

\section{Publisher's Note}

Springer Nature remains neutral with regard to jurisdictional claims in published maps and institutional affiliations.

Ready to submit your research? Choose BMC and benefit from:

- fast, convenient online submission

- thorough peer review by experienced researchers in your field

- rapid publication on acceptance

- support for research data, including large and complex data types

- gold Open Access which fosters wider collaboration and increased citations

- maximum visibility for your research: over $100 \mathrm{M}$ website views per year

At $\mathrm{BMC}$, research is always in progress.

Learn more biomedcentral.com/submissions 